\title{
REVISTAMARACANAN
}

Dossiê

\section{Escola Agrícola da Bahia de São Bento das Lages: experiências na implementação de instrução agrícola na Vila de São Francisco do Conde (1850-1890)}

\author{
Agricultural School of Bahia de São Bento das Lages: experiences in the \\ implementation of agricultural education in the Vila de São Francisco do \\ Conde (1850-1890)
}

Idalina Maria Almeida Freitas* Universidade da Integração Internacional da Lusofonia Afro-Brasileira, Brasil

Recebido em: 29 jan. 2019.

Revisado em: 18 maio 2019.

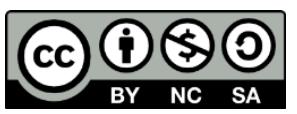

\footnotetext{
* Professora Adjunta, atuando no curso de Licenciatura em História, do Instituto de Humanidades e Letras da Universidade da Integração Internacional da Lusofonia Afro-brasileira, Campus dos Malês, Bahia. Doutora e Mestre em História Social pela Pontifícia Universidade Católica de São Paulo; e, graduada em História pela Universidade Federal do Ceará. (idaestevam@gmail.com)

CV Lattes: http://lattes.cnpq.br/2990853471289997.
} 


\title{
Resumo
}

Esse texto é fruto de uma pesquisa em andamento e tem como objetivo pensar a trajetória da EAB - Escola Agrícola de São Bento das Lages, situada na Vila de São Francisco do Conde, recôncavo baiano, na segunda metade do século XIX. A escola agrícola instituiu-se como espaço de desenvolvimento científico em torno da agricultura, destinou-se a formação de engenheiros agrônomos e de operariado agrícola "mais competente" e modernizado. O artigo pretende discutir a construção da escola, estrutura de funcionamento e ensino, dando destaque para o curso elementar na primeira fase da $E A B$, entendendo-o como um projeto de instrução pública para o pós-abolição. Evidenciar tal contexto permite a problematização de experiências na Vila de São Francisco do Conde, bem como historicidades de agentes que participaram em diferentes âmbitos desse modelo escolar.

Palavras-chave: Operários Agrícolas. São Francisco do Conde. Instrução Pública.

\begin{abstract}
This text is the result of ongoing research and aims to think about the trajectory of the EAB - São Bento das Lages Agricultural School, located in the village of São Francisco do Conde, Bahia, in the second half of the 19th century. The agricultural school was established as an area of scientific development around agriculture, destined to the formation of "more competent" and modernized agronomic engineers and agricultural workers. The article intends to discuss the construction of the school as well as its functioning and teaching structure, highlighting the elementary course in the first phase of the EAB, understanding it as a public education project for the post abolition period. By evidencing such context, it is possible to problematize experiences in Vila de São Francisco do Conde, as well as the historicities of agents who participated in different scopes of this school model.
\end{abstract}

Keywords: Agricultural Workers. São Francisco do Conde. Public Education. 
Libertem-se os negros, mas dê-se escolas agrícolas a este povo. Uma cousa sem a outra é a ruína completa de toda a nação.

\section{Ruínas e história...}

O município de São Francisco do Conde reúne até hoje um importante conjunto arquitetônico de herança colonial, no qual se encontram as ruínas da Imperial Escola Agrícola da Bahia. Pensando nos significados dessas ruínas para a história local, nacional e atlântica, esse artigo busca refletir a construção, estrutura de ensino e demais debates em torno do ensino agrícola na Bahia.

Traçando uma memória histórica da instituição, o livro Escola Agrícola da Bahia, do ano de 1934, é uma publicação que leva os nomes do interventor federal, o Capitão Juracy Montenegro Magalhães, do secretário de agricultura, o agrônomo Álvaro Navarro Ramos e, por fim, do diretor da EAB na época, engenheiro Archimedes Pereira Guimarães. Na secção de apontamentos históricos sobre a Escola Agrícola da Bahia, os autores buscavam apresentar suas diferentes fases, dividindo as crônicas sobre a escola em capítulos que seguiam tais épocas. Assim, embora não seja nosso objetivo e nem teríamos condições ainda para explorar completamente tais fases, julgamos ser importante pontuar as épocas, mostrando a abrangência da trajetória dessa instituição:

\footnotetext{
I - Da fundação do Instituto Bahiano de Agricultura até a instalação da escola (1859-1877)

II - Phase sob a direcção do Instituto Bahiano de Agricultura (1877-1904)

III - Phase da avocação pelo governo do Estado (1904-1911)

IV - Avocação pelo governo federal. Eschola Média ou Theorico Prática de Agricultura (1911-1917)

V - Reabertura sob o governo do Estado, para um aprendizado (1917-1920)

VI - Reabertura da escola agrícola da Bahia, sob o governo do estado, phase atual, a partir de Fevereiro de $1920 .^{1}$
}

A hipótese é que a Escola Agrícola da Bahia foi um projeto para o pós-abolição, percorrendo caminhos que promoveram uma circulação de ideias e projetos que conciliaram ciência e economia entre as colônias francesas, inglesas e americanas. Nasce influenciada pelos debates sobre nação, abolição e trabalho livre, criando um espaço destinado à instrução, o qual teve como um dos objetivos a formação de mão de obra e manutenção de um

\footnotetext{
${ }^{1}$ Escola Agrícola da Bahia. Bahia: Typographia do Commercio, 1934, p. 8. Pesquisa realizada no Instituo Geográfico e Histórico da Bahia (IGHBA).
} 
operariado agrícola "mais competente" e modernizado, justificando que a agricultura praticada por escravos e ex-escravos não era exercida de forma "profissional". ${ }^{2}$ Tal iniciativa possibilita problematizar quais foram as experiências dos sujeitos escravizados e livres no contexto da abolição e pós-abolição na Vila de São Francisco do Conde e quais as estratégias para reelaboração e manutenção desses sujeitos, nas mesmas esferas de trabalho.

Percebe-se, neste ínterim, que a criação de instituições com tal viés, ao passo que refletia as contradições da estrutura socioeconômica da província da Bahia no período, também demonstrava suas conexões com outros esforços em nível global, em se pensar formas e estratégias de instrução agrícola para o contexto local. ${ }^{3}$

A primeira Escola Agrícola da Bahia, inaugurada em 15 de Fevereiro de 1877, em São Bento das Lages, antigo Engenho das Lages, propriedade da Ordem de São Bento, teve origem no contexto pós-supressão do tráfico de escravos em 1850, dentre outras implicações que atingiram diretamente e reduziram a exportação do açúcar frente ao mercado mundial, consequência da falta de braços escravizados que mantinham o apogeu desse comércio. Tal empreitada contou com a articulação entre governo provincial, central e as elites açucareiras. Segundo Barickman, até o ano de 1880 os distritos canavieiros do recôncavo ainda empregavam muita mão de obra escrava, quando comparados aos da zona da mata pernambucana, que já vinham percebendo a abolição desde 1850 como "um longo processo". Deste modo, no recôncavo, a transição para a mão de obra livre não se deu de forma gradual, atuando como uma alternativa brusca para tentar sanar a "desorganização" do trabalho agrícola. $^{4}$

A origem e o funcionamento da $E A B$ eram subordinados às atividades do Imperial Instituto Bahiano de Agricultura, instituição criada em 18 de Novembro de 1859 e presidida pelo Imperador D. Pedro II. Sua criação está inserida no contexto da reunião de esforços para "salvar o aniquilamento da lavoura nacional", acompanhado de vários representantes da elite baiana. Assim, as ideias que circulavam em torno dessa esfera salvacionista do sistema econômico de base escravista, especialmente na região do recôncavo baiano, estão diretamente relacionadas e legitimam a criação da EAB.

Embora o foco central nessa investigação seja a Escola Agrícola, é inevitável pensar as duas instituições de forma isolada. Para a Escola Agrícola em específico tenho debruçado esforços no recolhimento de materiais, tais como o fundo de Instrução Pública - Ensino

\footnotetext{
${ }^{2}$ CAPDEVILLE, Guy. O Ensino Superior Agrícola no Brasil. R. bras. Est. pedag., Brasília, v. 72, n. 172, p. 229-261, set.-dez. 1991.

${ }^{3}$ Importante salientar que o Ministério do Império na Corte era o órgão que administrava o caráter dado a instrução nas províncias por meio da Lei n. 1331-A, de 17 de fevereiro de 1854. Regulamento da Instrução Primária e Secundária da Corte. No entanto, para a instrução agrícola segundo a Revista de Instrução Pública da Bahia, foram criados Institutos de Agricultura em todo o império, compreendendo o ensino da agricultura, ciências naturais e a s artes industriais. In: Revista de Instrução Pública da Bahia, 1872-1873. Disponível em: https://bit.ly/2S2IOf7. Acesso em: 04 out. 2018.
}

4 BARICKMAN, Berth J. Até a véspera: o trabalho escravo e a produção de açúcar nos engenhos do Recôncavo baiano (1850-1881). Afro-ásia, n. 21-22, p. 177-238, 1998-1999. 
Superior - Escola Agrícola (1865-1888) e as Correspondências recebidas da Câmara de São Francisco do Conde (1861-1880/1881-1889), os quais também revelam importantes falas sobre os processos de abolição e pós-abolição na Vila. ${ }^{5}$

Feitas essas considerações, é preciso observar que o texto está dividido em três partes essenciais para o seu entendimento: analisaremos primeiro a construção e estruturação da EAB - Escola Agrícola da Bahia, destacando, sobretudo, a força de trabalho livre, buscando entender fatores pertinentes a esse processo. Num segundo momento, a concepção, estrutura e fundamentos do curso elementar destinado a categorias sociais consideradas "desvalidas", mas com vinculação ao desejo de aprimorar o manejo agrícola, destacando nesse interim, as reações e penalidades sujeitas ao regulamento da escola. E, por fim, o artigo evidencia um contexto mais amplo do processo de pós-abolição na Vila de São Francisco do Conde, que consideramos como palco principal dos desdobramentos que envolvem a instrução pública, desenvolvimento científico e técnico, político, econômico e social na província.

\section{Construção, estrutura e formação agrícola na EAB}

Imagem 1 - Escola Agrícola da Bahia, São Bento das Lages, final da construção em 1872

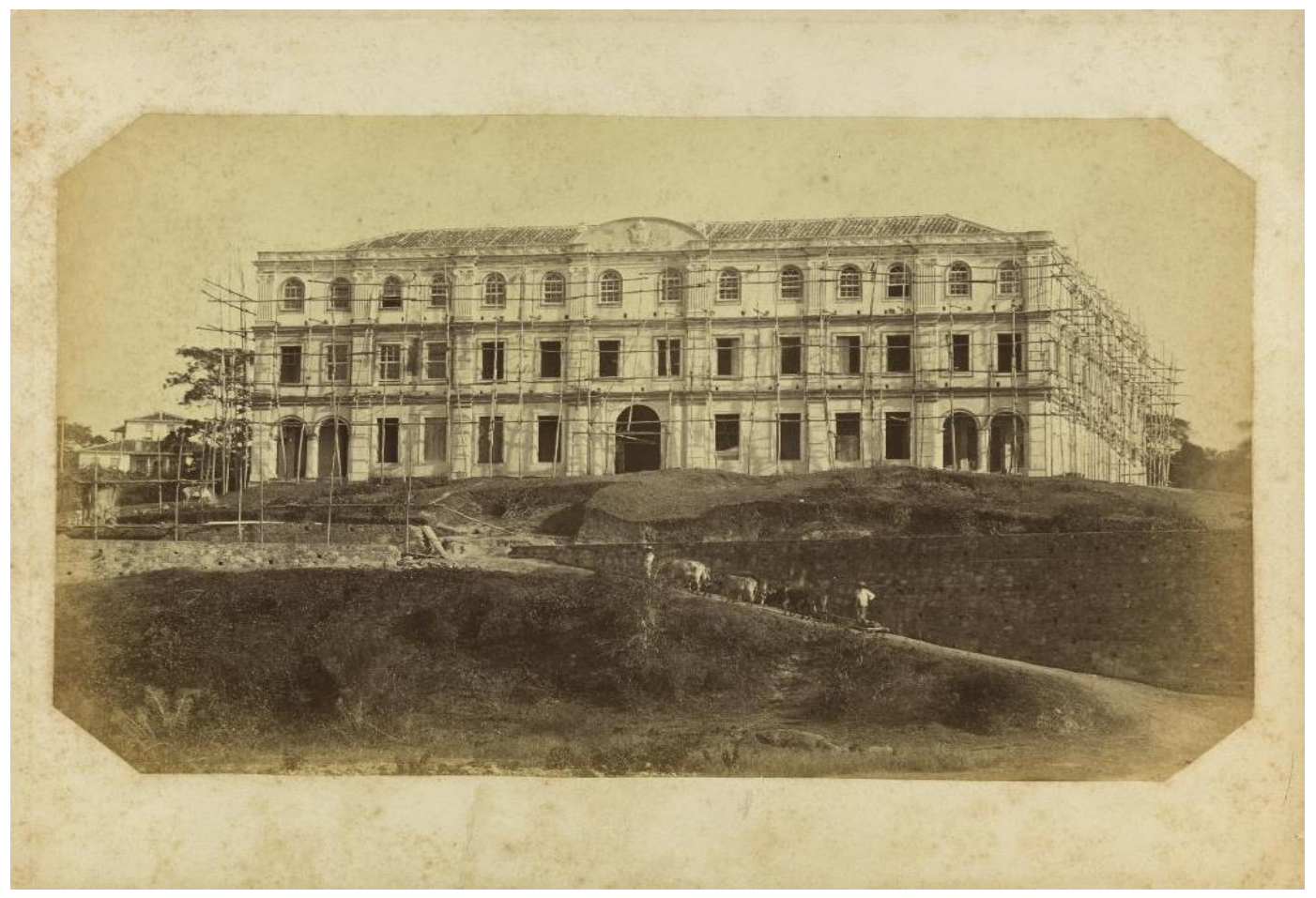

Fonte: brasilianafotografica.bn.br

\footnotetext{
${ }^{5}$ A documentação levantada sobre a instrução agrícola encontra-se no Arquivo Público do Estado da Bahia (APEB), Seção Colonial Provincial, na série Agricultura da Seção Histórica, distribuída em dois maços: entre 1859-1867 e 1868-1887.
} 
No ano de 1868 finalizam-se as obras de construção da Escola Agrícola, porém a sessão solene de inauguração acontece somente em 1877, a escola passa a funcionar em regime de internato e externato. As obras do prédio da escola agrícola foram conduzidas sob a inspeção do Diretor Interino e professor de Ciências Naturais (História Natural, Botânica e Zoologia) Louis Jacques Brunet, ${ }^{6}$ que, por meio das correspondências trocadas com o Presidente da Província, demonstrou grande empenho na aquisição de pessoas e artefatos para a escola, além de conjecturar sobre as condições físicas ideais para a conclusão da grandiosa obra. Vale lembrar que a liderança de Brunet no âmbito da Escola Agrícola, no momento em questão, denota o aspecto da instituição como espaço de práticas científicas que davam suporte às atividades econômicas. Podemos entendê-la, por sua vez, a partir dos pressupostos da história da ciência, compreendendo sua importância no campo da institucionalização da ciência no país. As movimentações das elites locais, estado imperial e de intelectuais nacionais e estrangeiros que participaram da escola revelam as dimensões de um pragmatismo para os estudos da natureza que se inauguram no século XVIII, percorrendo caminhos que promoveram uma circulação de ideias e projetos que conciliaram ciência e economia entre as colônias francesas, inglesas e americanas. $^{7}$

No ano de 1864, a construção, segundo Brunet, "marcha seguramente". A segurança das obras é protagonizada pelo conjunto de operários envolvidos na empreitada. Os trabalhos iniciaram com o número de "20 africanos livres da localidade". ${ }^{8}$ A saída desses africanos é informada pelo diretor no ano seguinte, quando o mesmo entusiasmadamente ressalta ter alugado, ao preço de 640 reais diários, os moradores dos arrabaldes, onde "servirão como trabalhadores e serventes conforme a melhor aptidão de cada um, alguns que não estavam acostumados com a enxada já vão indo suficientemente". ${ }^{9}$

Ainda no mesmo ano, o naturalista entrava em diálogo com a província da corte reclamando a necessidade de mais pedreiros e destes serem dispensados do recrutamento pelo Instituto Agrícola, em clara referência à Guerra do Paraguai. ${ }^{10}$ Ele menciona a necessidade de não embarcar "o pedreiro Manuel de Jesus e o carapina Pedro José dos Santos". ${ }^{11}$ Outro trabalhador, de nome Germano Dias, teria sido conduzido pela guarda nacional, saindo do

\footnotetext{
${ }^{6}$ Naturalista francês da cidade de Moulins que chegou ao Brasil na segunda metade do século XIX. Foi o primeiro diretor interino da Escola Agrícola de São Bento das Lages, sendo responsável por todo o processo de construção da escola. Ver mais em: https://bit.ly/32eQmil. Acesso em: 04 out. 2018.

7 KURY, Lorelai. Homens de ciência no Brasil: impérios coloniais e circulação de informações (1780-1810). História, Ciências, Saúde - Manguinhos, Rio de Janeiro, v. 11, supl. 1, p. 109-129, 2004.

${ }^{8}$ APEB. Correspondências Imperial Instituto Bahiano de Agricultura. Série Agricultura, 1864.

9 Idem.

${ }^{10}$ Sobre a participação de soldados baianos na Guerra do Paraguai, ver: RODRIGUES, Marcelo Santos. Voluntários da pátria na guerra do Paraguai: a participação da Bahia no conflito. 2001. Dissertação (Mestrado em História) - Faculdade de Filosofia e Ciências Humanas, Universidade Federal da Bahia, Salvador.

${ }^{11}$ APEB. Correspondências Imperial Instituto Bahiano de Agricultura. Série Agricultura, 1864.
} 
vapor de Santo Amaro, por meio de recrutamento. A direção interina solicitou soltura do pedreiro ao chefe da guarda, alegando que a evasão do tal homem poderia afugentar outros operários e serventes da obra, assim reforça-se, nos idos de 1866, "ser conveniente, dar as providências a fim de renovar a isenção do recrutamento em favor do Instituto Imperial". ${ }^{12} \mathrm{O}$ recrutamento também interferira, certamente pela ausência de mão de obra, no fornecimento de madeiras para a construção, oriundas dos portos de Belmonte e Canavieiras.

A mão de obra livre, desde a segunda metade do século XIX no recôncavo baiano, conforme expôs Barickman, era composta por feitores, caixeiros, ferreiros, carpinteiros, pedreiros, artesãos, entre outros. ${ }^{13}$ Entretanto em tarefas de roçagem, plantio e limpeza da cana nos engenhos, até essa data de 1850, não era comum a utilização dessa mão de obra. No período de construção da escola agrícola, a Guerra do Paraguai forneceu bons motivos para que esses homens livres construíssem outra opção ao recrutamento, muito embora também não se empenhassem tanto no trabalho de serventes, o que gerava inúmeras críticas por parte da direção da escola, ávida pela conclusão da obra.

A Escola Agrícola, após a sua construção, tornou-se um edifício destinado à moradia e atividades pedagógicas dos alunos, tinha casas para os professores e uma área externa destinada aos trabalhos no campo de ensaio: curral, estribaria e cercados. O edifício também possuía internamente capela, museu com 3.462 exemplares de anatomia, paleontologia, esqueletos, imitações em gesso, mamíferos, aves, crustáceos, peixes, etc. ${ }^{14} \mathrm{~A}$ partir do documento que regulamentava as atividades na $E A B$, pode-se traçar um esboço da estrutura física e humana da escola, composta por: uma congregação de lentes mais a presença do diretor, o diretor nomeado pelo Imperial Instituto de Agricultura, professores, secretário, ecônomo, chefe de serviços agrícolas, bibliotecário, capelão, médico, enfermeiro. Museus e gabinetes, sendo eles: gabinete de physica, gabinete de zoologia e geologia, laboratório químico, museu de produtos agrícolas, florestais e de máquinas, gabinete de engenharia rural, gabinete de desenho, gabinete veterinário, sendo que tais gabinetes ficam a cargo dos professores, cujas cadeiras servirem e também dispõem que todos os objetos existentes nos gabinetes e museus deveriam estar classificados. ${ }^{15}$

No dia 22 de Junho do ano 1871, em correspondência endereçada ao Barão de Sergimirim, presidente do Imperial Instituto Bahiano de Agricultura, Louis Jacques Brunet relatava sua viagem à Europa e ao continente africano, a fim de adquirir acervo para a Escola Agrícola:

\footnotetext{
12 APEB. Correspondências Imperial Instituto Bahiano de Agricultura. Série Agricultura, 1864.

13 BARICKMAN, Berth J. Até a véspera: o trabalho escravo e a produção de açúcar nos engenhos do Recôncavo baiano (1850-1881). Afro-ásia, n. 21-22, p. 177-238, 1998-1999.

14 TOURINHO, Maria Antonieta de Campos. A instrução agrícola e a crise da economia açucareira na segunda metade do século XIX. 1982. Dissertação (Mestrado em História Social) - Programa de Pósgraduação em História da Universidade Federal da Bahia, Salvador, p. 131-132.

15 IGHB. Imperial Instituto Baiano de Agricultura, Regulamento Geral da Eschola Agrícola da Bahia, Bahia: 1889, p. 1-34.
} 
Pondo-me aqui em relação com variadas pessoas competentes, para dar-me as informações as mais positivas sobre o fim a que o Imperial Instituto se propõe, soube que seria preferível comprar na África, no Senegal, uma parte dos animais de raça. Um amigo do general Faidherb, que a pouco governava a colônia do Senegal, afiançou-me, como várias pessoas que consultei depois, que poderia adquirir em S. Luiz do Senegal, magníficos e excelentes cavalos, cuja introdução no Brasil seria preferível a dos cavalos Árabes, são os cavalos indígenas do país dos Dovichs, que são infatigáveis e que gozam das mais qualidades dos cavalos Árabes, dos quais eles são antiquíssimos descendentes [...] Estando hoje na França numerosas as pessoas de todas as classes completamente derrotadas, talvez seria bom aproveitar a ocasião para adquirir um jardineiro, um lavrador, um mestre de arado e um moço que saiba tratar de animais e gados na estribaria. Um moço de 30 anos, inteligente, instruído, ativo, costumado aos países tropicais, aluno de várias escolas agrícolas, que tem feito as suas provas na Algeria e outras colônias Francesas, e por isso condecorado com a legião de honra e outras ordens; sem falar em várias medalhas obtidas nos concursos agrícolas e na exposição de 1857, atualmente empregado ao governo Francês, como diretor nas plantações nas colônias, tendo desejo para os seus estudos particulares, de passar um ano ou dois no Brasil, tem-me proposto de ir durante esse tempo professar e dirigir ao mesmo tempo as plantações em S. Bento. ${ }^{16}$

Louis Jacques Brunet é um personagem onde o trabalho com a ciência conectou diversos mundos: o da política, da economia, intelectualidade e ciência em si. Interlocutores desses mundos promoveram uma circulação de ideias e produtos econômicos. ${ }^{17}$ Uma trajetória transnacional em conexão com um mundo europeu mais amplo, especificamente as colônias francesas. E para a aquisição de materiais botânicos, era imprescindível a construção de órgãos científicos. A viagem do naturalista à Europa contou com a subvenção do estado Imperial, capital em torno de 96:000\$000 e a compra de materiais didáticos importados com isenção de impostos. Ele faz uma longa descrição ao diretor do Instituto sobre os lugares por onde passa e suas impressões, além de recolher vegetais, plantas e animais:

Subindo o rio Senegal 30 ou 40 léguas acima, encontrou-se os camelos dos Mouros Trarsos, os zebus e os bois das tribos Peuls, os grandes carneiros sem cabelos de Galam: Estes gados e animais tomados em um clima igual ao do Brazil, aclimatarão-se com mais facilidade que as raças da Europa. Além disto teve a ocasião de ver o Diretor do Jardim botânico de Richard Toll no Senegal, que confirmou-me as informações acima e prometeu-me de pôr a minha disposição, todos os vegetais alimentares dos países tropicais, como as variedades de cana d'açúcar, 18 variedades de algodoeiro que são cultivadas no jardim, e uma espécie nova de cafeeiro muito miúda, indígena e espontânea n'África ocidental. ${ }^{18}$

Richard Toll era uma província colonial francesa, também conhecida como o Château de Baron Roger, em homenagem Jean Michel Claude Richard. Ele era um naturalista francês diretor do jardim botânico do Senegal, foi condecorado com a Legião de Honra francesa e criara no ano de 1816 o jardim botânico citado na descrição de Brunet. Não temos certeza se

\footnotetext{
${ }^{16}$ APEB. Correspondências do Imperial Instituto Agrícola da Bahia. Série Agricultura (1868-1887), Seção de Arquivo Colonial-Provincial.

17 Naturalista francês da cidade de Moulins, chega ao Brasil na segunda metade do século XIX, foi o primeiro diretor interino da Escola Agrícola de São Bento das Lages, sendo responsável por todo o processo de construção da escola. Ver mais em: https://bit.ly/32eQmil.

${ }^{18}$ APEB. Correspondências do Imperial Instituto Agrícola da Bahia. Série Agricultura (1868-1887), Seção de Arquivo Colonial-Provincial. Grifo nosso.
} 
Brunet, nessa viagem, de fato encontrara-se com Richard, tendo em vista que ele em 1831 estabeleceu-se na Île de la Reunión, também território francês na época. No entanto, chama a atenção uma rede de trocas de produtos e ideias que gerenciavam o preparo e desenvolvimento das áreas agrícolas de colônias em diferentes continentes. Em tempo, Jean Michel Claude Richard na Île de la Reunión envolvera-se em uma polêmica científica em 1841, quando o jovem escravo de doze anos Edmond Albius (1829-1880) descobre o método prático de polinização da vanilla. Richard atribuiu a si todas as honras, alegando que havia ensinado o método ao jovem três ou quatro anos antes. As dúvidas só foram afastadas definitivamente no fim do século XX, dando a Edmond o reconhecimento e a paternidade da descoberta. ${ }^{19}$

Voltando a correspondência de Brunet, este recomenda para atuação em São Bento das Lages, um "jovem aluno de várias escolas agrícolas" que teria realizado trabalhos em colônias francesas e na exposição de 1857, temática ainda recorrente entre as correspondências da EAB nos anos que sucederam:

Apesar disso, penso que brevemente poderemos contar com um condutor de trabalhos práticos, procedente das Antilhas, o qual não tardará a ser contratado mediante a solicita intervenção do Governo da Província, ficando d'este modo satisfeita uma das maiores necessidades do ensino prático. ${ }^{20}$

Importante perceber que além das deliberações sobre as aquisições de acervos de animais, plantas e sementes, assim como objetos técnicos e acadêmicos para a escola, havia uma preocupação de importar mão de obra qualificada, sobretudo em espaços de intenso desenvolvimento da agricultura de viés escravista: como a Algeria, Antilhas e outras colônias francesas. Esses indícios reforçam o que pretendemos também explorar no decorrer da pesquisa, no que se refere à circulação a nível atlântico de saberes científicos que gerenciavam o mundo agrícola no recôncavo.

A cultura e o desenvolvimento de técnicas agrícolas foram fenômenos de abrangência atlântica. ${ }^{21}$ Nesse sentido, situa a Vila de São Francisco do Conde em um contexto mais amplo, de circulação de ideias e pessoas, com isso, desenvolvem-se as atividades de formação

${ }^{19}$ Bulletin de l'Agence générale des colonies 1919-1934. Disponível em: https://bit.ly/2S4Sftk. Acesso em: 08 nov. 2018.

${ }^{20}$ Correspondência do Diretor da EAB, Dr. Francisco dos Santos Silva, ao presidente do Imperial Instituto Bahiano de Agricultura, o Barão de São Francisco. Eschola Agrícola da Bahia em São Bento das Lages, março de 1886.

${ }^{21}$ As possibilidades e vantagens de se lançar um olhar Atlântico visto de baixo para a história local do recôncavo baiano, pode-se oferecer elementos para reconstruir experiências históricas e de diferentes sujeitos, por meio de outra escala de observação. É possível perceber similaridades e diferenças, pensando o Atlântico como um espaço de conexões, no qual cada uma das partes tem a sua importância e o seu papel. Pensar as articulações locais entre algumas regiões que compunham o oceano Atlântico, leva-nos a perceber aspectos demográficos, econômicos, políticos, sociais e culturais, articulando sempre as especificidades locais e a dinâmica geral. O mundo atlântico seria o encontro de mundos distintos que não deixavam de possuir experiências, em certa medida, comuns. O conceito de história atlântica busca a articulação entre o local e o global, a fim de pensar em especificidades regionais sem, contudo, esquecer o contexto no qual estava inserido, isto é, o Atlântico. A economia atlântica interferia nas relações econômicas domésticas, a lógica de dominação desenvolvida nos quatro cantos do oceano também necessitava da incorporação das elites locais. Por mais distantes que pudessem estar, a vivência local estava conectada ao contexto amplo do Atlântico. 
pedagógica em níveis de formação superior e elementar, ou seja, filhos da elite agrária e órfãos ou filhos de pequenos lavradores rurais. A preocupação com a instrução agrícola também surge como uma forma de compensação frente ao fim do trabalho escravo, tendo em vista que a educação com forte vocação para o trabalho correcional foi uma temática recorrente quando pensamos em educação no Império, mais especificamente articulada à Lei do Ventre Livre, de 28 de setembro de 1871.

\section{O curso Elementar e a formação de operários agrícolas}

A formação dos alunos da Escola Agrícola era dividida em cursos superior e elementar. O curso superior destinava-se a formação em conhecimentos tecnológicos mais avançados, no intuito de formar engenheiros agrônomos seguindo alguns critérios para a admissão por meio do regulamento da Escola que exigia: "ter completado dezesseis anos e ser habilitado nas disciplinas de português, francês, geografia, aritmética, álgebra, geometria e trigonometria". Tal público se encontrava dividido, também, entre pensionistas e gratuitos, ambos com requisitos e exigências em comum, tais como: "ambos serem vacinados e para os gratuitos, provar que não tem meios, pertencer às famílias que pratiquem a agricultura ou ser órfão de pai e de mãe ou ser filho de mãe viúva". Além disso, para admissão, segundo o regulamento, os exames necessários à matrícula, eram: "Gramática, leitura e escrita portuguesa; Gramática, leitura e tradução francesa; Geografia do Brasil". ${ }^{22}$ Entre a modalidade de alunos gratuitos, os preferidos pela ordem eram em primeiro lugar, os filhos de família que fizessem profissão de agricultura.

No ano de 1878, um ano após a abertura da Escola Agrícola, o então diretor-geral de instrução da Bahia, Emílio Lopes Freire Lobo, consultou o Presidente da Província Antônio de Araújo de Aragão Bulcão sobre os "ingênuos", categoria de indivíduos que nasceram livres e nunca foram escravos, porém filhos de escravas. O diretor desejava saber se após a Lei do Ventre Livre de 1871 essas crianças seriam admitidas em escolas públicas, aceitas pelo sistema de instrução contribuindo para o "progresso e civilização". ${ }^{23}$ No livro $A$ educação dos negros: uma nova face do processo de abolição da escravidão no Brasil, Marcus Vinícius Fonseca reflete sobre as propostas educacionais para crianças negras, entre 1871 e 1888. Discutidas nos congressos agrícolas organizados entre os estados do Rio de Janeiro e

\footnotetext{
22 IGHB, Imperial Instituto Baiano de Agricultura, Regulamento Geral da Eschola Agrícola da Bahia, Bahia: 1889, p. 23.

${ }^{23}$ NUNES, Anttonieta d'Aguiar. Sinopse da História da Educação baiana até o Período Imperial. Revista IGHB, Salvador, v. 111, p. 23-57, jan.-dez. 2016.
} 
Pernambuco, muitas delas refletiam a nova sociedade que emergiria da superação da escravidão, pelo destino e futuro do trabalhador negro nacional. ${ }^{24}$

Para o curso elementar a definição de formação, segundo o estatuto, é de "operário agrícola", formação voltada para despertar o gosto pela agricultura, fixando-os no campo como mão de obra, as turmas eram compostas por meninos com idade a partir de 12 anos, filhos de pequenos lavradores, órfãos de São Joaquim e meninos abandonados da capital.

\begin{abstract}
Além do curso técnico superior, a Escola criou um curso chamado elementar, o qual é frequentado por meninos órfãos ou filhos de lavradores desvalidos. Tem por objectivo esse curso preparar operários agrícolas. O ensino que esses meninos recebem é a instrução primária e religiosa, de par com as práticas do campo. A Escola ministra-Ihe gratuitamente tudo quanto precisão. A matrícula pode elevar-se até 30 alunos: presentemente, porém contam apenas 22, não só em virtude de haverem se retiraro ao expirar o prazo de três anos, tempo determinado pelo Regulamento para o aprendizado, como também porque poucos são os pais que de boamente renunciam ao trabalho de seus filhos, momento quando estes atingem a idade de 10 a 12 anos, época em que lhes podem já prestar algum serviço. ${ }^{25}$
\end{abstract}

O curso tem a duração de três anos e a estrutura curricular é composta de: noções elementares de geografia, gramática, contabilidade, desenho linear e mecânico. Estes alunos também aprendem catecismo, música e praticam durante cinco horas por dia nos campos os trabalhos de culturas agrícolas, com aprendizagem do manejo e uso de instrumentos. "Dispõem além disto, de alguns instrumentos agrícolas como sejam charruas, arados, rolos para o trabalho". ${ }^{26}$ No Inventário dos Objectos - São Bento das Lages, pertencentes a Escola Agrícola em 1873, "as ferramentas da Oficina: 68 ferramentas, tenazes, puá, martelos, torquezas, formões, serras, e etc. ${ }^{27}$ Segundo o capítulo VIII do regulamento da EAB, ao chefe do serviço agrícola compete a direção do ensino elementar, "dirigir os operários agrícolas, que Ihe prestarão obediência e respeito, velar pela conservação de boa ordem de aparelhos e máquinas". 28

Considera-se que a "falta de braços", em tantos momentos discutida entre as elites senhoriais e demais autoridades nas últimas décadas do Império, impôs novas demandas à sociedade sobre as formas de empregar e qualificar principalmente pessoas "pobres" e de

\footnotetext{
${ }^{24}$ FONSECA, Marcus Vinícius. A educação dos negros: uma nova face da abolição da escravidão no Brasil. Bragança Paulista: EDUSF, 2002.

25 APEB. Relatório do Diretor da Escola Agrícola de São Bento das Lages, 28 de janeiro de 1886. Correspondências do Imperial Instituto Bahiano de Agricultura, Série Agricultura, Seção de Arquivo Colonial-Provincial. "Em cumprimento do ofício de V. Exa. de 18 do corrente, e a que tive a honra de responder em parte, passo às mãos de V. Exa. relatório do Diretor da Escola Agrícola d'este Estabelecimento, como o qual completo as informações que me foram exigidas. Encaminhada ao Illmo. Exmo. Senhor Conselheiro Theodoro Machado Freire Pereira da Silva Me. D. Presidente da Província."

${ }^{26}$ Inventário dos Objectos Existentes em S. Bento das Lages, em $1^{\circ}$ de outubro de 1872. Bahia: Imprensa Econômica, 1874; APEB. Correspondências do Imperial Instituto Bahiano de Agricultura, Documentos da Série Agricultura, Seção de Arquivo Colonial-Provincial.

${ }^{27}$ Idem.

${ }^{28}$ IGHB, Imperial Instituto Baiano de Agricultura, Regulamento Geral da Eschola Agrícola da Bahia, Bahia: 1889, p. 14 e 15.
} 
"cor". Dentre algumas dessas experiências de escolarização no contexto da sociedade baiana, encontra-se a Casa Pia e Colégio de Órfãos São Joaquim. A admissão de menores entre 7 e 9 anos era o perfil que a Casa Pia exigia. ${ }^{29}$ Oferecia a crianças e jovens nível de instrução, embora sendo uma instituição voltada para a caridade, priorizava a formação de mão de obra, em oficinas de trabalhos artesanais, alguns até os 18 anos, em certos casos encaminhados para empregos assalariados ou para o arsenal da marinha. O perfil das categorias sociais das famílias de alunos que estiveram em São Joaquim, traçado por Alfredo Matta em pesquisa sobre a instituição, além de nos fornecer elementos para pensar as transformações socioeconômicas da capital baiana, também demonstra, por extensão, o perfil de alguns alunos que adentraram a escola agrícola.

A análise feita entre os anos de 1825 e 1910, que o escopo da pesquisa de Alfredo apresenta, demonstra uma predominância, embora de forma alternante, do alto índice de mães solteiras e viúvas. Apresentou também ingresso predominante entre 1840 e 1875, de filhos legítimos, ou seja, filhos de casais legais, reflexo da organização familiar da sociedade baiana no período. ${ }^{30}$ Alfredo também em sua investigação por meio do perfil familiar percebe que:

\begin{abstract}
a Casa Pia tinha a política de permitir, preferencialmente, o ingresso de menores brancos em detrimento de pardos e outras etnias. Negros e crioulos eram quase totalmente excluídos. Da inauguração do orfanato, em 1825, numa cidade onde $59,1 \%$ dos mendigos e vadios eram crioulos ou negros, nenhum ingresso na instituição era negro ate 1858. O primeiro negro a ingressar na Casa (1858) foi apoiado por um abaixo assinado de toda a Mesa ao Presidente da Província, justificando o pedido por meio de referências ao merecimento e a história de vida de sua mãe. Em 1873, a Mesa destaca haver deixado entrar um menino de pele mais escura, alegando que como este já estava no Colégio não poderia mais ser retirado. Um caso realmente especial. Desse modo pode-se dizer que a discriminação racial vigorava na Casa Pia. ${ }^{31}$
\end{abstract}

A relação da Casa Pia com o ingresso de crianças criolas, libertas e escravas era praticamente inexpressiva em relação ao público geral, o que demonstra, na análise do autor, a tentativa de afastamento da instituição, de populações ligadas, em alguma instância, à escravidão. Ainda para o autor, os dados da Casa Pia podem servir de indício de que "os negros e escravos foram excluídos sistematicamente da formação de uma nova classe trabalhadora baseada no trabalho assalariado e não mais cativo", 32 objetivo não tão semelhante ao da EAB,

\footnotetext{
${ }^{29}$ A Casa Pia e Colégio dos Órfãos de São Joaquim, ex-Noviciado da Anunciada da Jequitaia (1704), está localizada na parte baixa de Salvador, no sopé da Montanha, à margem da avenida que leva à península de Itapagipe em Salvador - Bahia. Os estatutos originais da Casa Pia de Órfãos de São Joaquim foram aprovados em 30 de outubro de 1828. Tendo nascido sob a proteção da família real, era natural que a instituição recebesse toda a atenção e cuidados do governo de D. Pedro I. A tradição desta instituição era voltada a fim de direcionar as populações de menores órfãos ou carentes, para dar-Ihes instrução profissional e tomá-los úteis à sociedade. Cf.: MATTA, Alfredo Eurico Rodrigues. Casa Pia Colégio de Órfãos de São Joaquim. De recolhido a assalariado. 1996. Dissertação (Mestrado em História) - Programa de Pós-graduação em História da Universidade Federal da Bahia, Salvador.

${ }^{30}$ Idem.
${ }^{31}$ Idem.
${ }^{32}$ Idem.
} 
muito embora não identificarmos, até a presente análise, uma discussão em torno de salário para essa mão de obra.

O desejo aqui, por meio da pesquisa de Alfredo, é tentar realizar uma aproximação do perfil racial e sociofamiliar dos alunos matriculados no curso elementar da escola agrícola, uma vez que alguns destes meninos tiveram também passagem pela Casa da Pia na capital, como demonstra o ofício abaixo: "Tendo em virtude de ordem de V. Exa. apresentados á matricula nesta Escola, quatro alunos do Colégio dos Órfãos de São Joaquim, veio entre eles o de nome José Lopes de S. Joaquim, com 12 anos de idade e apenas preparado em Português". ${ }^{33}$

O menino José Lopes não é admitido na escola agrícola por não apresentar os requisitos exigidos no regulamento da mesma, que, segundo o documento em questão, já sinalizavam quais deveriam ser as "condições tão claramente enumerados no ofício de V. Exa. á mesa d'aquele colégio". ${ }^{34}$ Pode-se perceber que mesmo neste caso, o estudante não sendo aceito, a troca de correspondências entre as duas instituições, Escola Agrícola e o Casa Pia - Orfanato São Joaquim, era feita, uma vez que ainda permaneceram os outros três alunos que vieram com José. As interlocuções foram realizadas via respectivos diretores das duas instituições, com cópia direta ao presidente da província.

Os alunos da instrução agrícola, denominados de futuros "operários agrícolas", tiveram uma formação por meio do curso elementar, cujo eixo central era a inserção qualificada no mundo do trabalho livre. Tourinho afirma que as fugas e processos de indisciplina eram frequentes, assim como o aumento do número de estudantes que a documentação dá conta até meados de 1890. Havia um conflito entre as formas de se pensar a disciplina e a rotina de formação nesse curso, com divergências entre aqueles que eram submetidos.

Em 7 de fevereiro de 1897, a diretoria da Escola Agrícola de São Bento das Lages envia um ofício ao Chefe de Polícia da Província informando que quatro alunos haviam se ausentado do curso elementar, eram eles: Olivio Emiliano de Menezes, Graciliano Menezes Dória, Francisco Alves de Oliveira e Constantino Alves de Oliveira. Todos eles eram moradores de engenhos da região da Vila de São Francisco do Conde. O desejo e apelo feito pelo diretor da escola ao chefe de polícia era que os alunos retornassem a escola, a fim de que assim como os outros, completassem os três anos de permanência, que era cláusula expressa no regimento da escola e cuja "a polícia das aulas" era responsável. A permanência desses estudantes no processo de formação que a escola oferecia era tida como um "grande sacrifício" e, portanto, deveria ser dado algum retorno por parte destes, no âmbito de serviços que poderiam ser prestados nas lavouras após toda a formação. O sacrifício ao qual a diretoria se referia possivelmente dialogava com as constantes limitações orçamentárias que por muitas vezes circulavam nas correspondências do Instituto de Agricultura. Lembrando que as receitas da

${ }^{33}$ Diretoria da Escola Agrícola de São Bento das Lages, 3 de agosto de 1876. Reposta ao officio enviado do Colégio S. Joaquim, 1876. APEB, Série Instrução Pública - Ensino Superior Escola Agrícola 1865-1881, Seção de Arquivo Colonial-Provincial.

${ }^{34}$ Idem. 
escola provinham das pequenas pensões que os alunos do curso superior pagavam, subvenções que o Instituto, o Estado Imperial e a Província concediam todos os anos. ${ }^{35}$

Retomando à fuga dos estudantes do curso elementar, a diretoria da escola alerta ao chefe de polícia para apreensão em casos semelhantes, sugerindo ser uma atitude recorrente as tais fugas:

A vista do que venho de expor, peço permissão a V. Exa. para lembrar-lhe que podem eles ser apreendidos pela polícia, convenho recomendar aos Delegados dos Termos de Santo Amaro e de São Francisco, que auxiliem eficazmente a esta Diretoria em casos idênticos, como por alguns antecessores de V. Exa. já foi feito. ${ }^{36}$

A atuação conjunta com a polícia é expressa no sentido de prestar um grande serviço à sociedade e a própria instituição escolar, lembrando a função que exerce o curso elementar, que é "formar operários e regentes agrícolas encaminhando para o trabalho honesto, inteligente, os filhos das classes desvalidas, d'ele tão desviados". 37 o tempo do "empregador", nesse caso, aquele que forma para o trabalho agrícola, cuida e disciplina para que esse tempo não seja desperdiçado, o valor do tempo entre formação e retorno material, a partir dessa formação, é imprescindível. São aprendizados para deter o tempo e a disciplina de uma vida produtiva.

No projeto da Escola Agrícola, criado pelo instituto imperial de agricultura da província, o diretor também poderia admitir aos trabalhos nos campos, estrebarias, operários livres ou escravos "á pedido do seu senhor", que quisessem aprender diferentes processos agrícolas, como simples operários, em um determinado período de tempo, e ao final receberiam um certificado de conduta e aptidão. ${ }^{38}$

\section{Abolição e pós-abolição na Vila de São Francisco do Conde}

No dia 19 de Maio de 1888, Egas Moniz Barreto de Aragão, conhecido como Barão Moniz de Aragão, presidente da Câmara da Vila de São Francisco do Conde e proprietário de engenhos na região, recebeu um ofício por parte do Ministério da Agricultura, Comércio e Obras Públicas, cujo objetivo era levar ao conhecimento dos munícipes a existência de uma lei

\footnotetext{
${ }^{35}$ Escola Agrícola da Bahia em São Bento das Lages, 2 de março de 1886. Correspondências do Imperial Instituto Bahiano de Agricultura. Relatório do Diretor da Escola Agrícola de São Bento das Lages, 28 de janeiro de 1886. Documentos da Série Agricultura, Seção de Arquivo Colonial-Provincial.

${ }^{36}$ Escola Agrícola da Bahia em São Bento das Lages, 2 de março de 1886. Correspondências do Imperial Instituto Bahiano de Agricultura. Relatório do Diretor da Escola Agrícola de São Bento das Lages, 28 de janeiro de 1886. Documentos da Série Agricultura, Seção de Arquivo Colonial - Provincial.

37 Idem.

38 Projecto de uma escola de agricultura para a Província da Bahia, pelo Imperial Instituto Agrícola da mesma Província. Apud: TOURINHO, Maria Antonieta de Campos. A instrução agrícola e... Op. cit., p. 251.
} 
extinguindo a escravidão, recomendando a sua pronta execução. ${ }^{39}$ O Barão, em vários momentos do seu texto de resposta ao ofício, pontua a "vagabundagem" e a "rebeldia", além do receio evidente de que esses libertos reclamassem o direito e continuassem a viver nas propriedades dos seus ex-senhores, em "proveito exclusivo" ou como "intrusos". São passagens que expressam a sua interpretação acerca desse processo e do que teria se instalado, segundo ele, como "entusiasmo delirante", ou seja, a liberdade dos ex-cativos. O historiador Walter Fraga analisou a forma como a abolição foi recepcionada com festa e extrema euforia em diversas localidades do recôncavo baiano e de como, aliado a isso, o sentimento de medo, desconfiança e reprovação dos antigos senhores, ocasionou intensos debates nas câmaras municipais, jornais, dentre outros espaços, no que estes qualificaram como "desobediência", "anarquia" e "vadiagem" e de como as concepções do que seria a liberdade para esses sujeitos adquiriu sentidos completamente diferentes. Possivelmente, como ainda expôs Fraga, a perca da autoridade por parte dos senhores, sobretudo no universo do trabalho, corroborara com o quadro de ruína e miséria, que, segundo os senhores de engenho, encontrava-se todo o recôncavo naquele período. ${ }^{40}$

Na série de documentos intitulados "Lavoura", endereçado ao presidente da província entre os anos de 1853 e 1885, o senhor M. Pinto da Rocha indica que a necessidade de braços, pode ser suprida pela "gente livre", no entanto esse grupo "não sujeita-se a limpar canas, senão quando estão pequenas, não querem ser foguista das fornalhas, não aceitam outros serviços pesados do engenho", e que compareciam apenas alguns dias no trabalho causando problemas na moagem. O nobre senhor compara de forma irônica ao tempo do recrutamento referindo-se à Guerra do Paraguai, diz que esses sujeitos trabalhavam até por pequenos salários e em todos os tipos de trabalhos nas fábricas, frente "ao receio de serem recrutados, ou de sofrerem as fadigas mortais das guerras, aconselhava-os ao honesto trabalho". ${ }^{41} \mathrm{~A}$ ideia de produção para subsistência também era duramente criticada, segundo ele: "a pescaria inútil de piabas" irritava-o por não estar na lógica produtiva em larga escala, adentrava também numa esfera de controle do próprio tempo e trabalho. Diversas são as justificativas que clamam ao poder provincial a manutenção da civilização por meio do trabalho nas lavouras, dentre elas estão a moralização das famílias, a prevenção de furtos e roubos que esses indivíduos estariam entregues, a honestidade e o lucro, dentre outros benefícios que só o trabalho na agricultura regular poderia possibilitar. Interessante perceber que no contexto do recôncavo baiano, mesmo frente a insubordinações do pós-abolição por parte dos homens e mulheres livres, a busca pelos trabalhadores livres nacionais foi requisitada e posteriormente reorganizada a partir de outras estratégias. A instrução pública agrícola é uma delas, desse

39 Correspondências do Paço da Câmara Municipal da Villa de São Francisco da Barra do Sergipe do Conde, 19 de maio de 1888. APEB, Seção de Arquivo Colonial-Provincial.

40 FRAGA FILHO, Walter. Encruzilhadas da liberdade. História de escravos e libertos na Bahia (18701910). Campinas: Ed. Unicamp, 2006, p. 120-160.

${ }^{41}$ Documentos da Série: Agricultura, Lavoura (falta de mão de obra para o trabalho) 1853-1885. APEB, Seção de Arquivo Colonial-Provincial. 
modo, contrariando o que a historiografia clássica do trabalho no Brasil expôs sobre a "transição" da mão de obra escrava para a livre, sinônimo de imigração europeia, as fontes locais sugerem que essa transição pode ser pensada a partir de uma reconfiguração das relações de trabalho, de forma brusca e não gradual, tendo protagonismo de trabalhadores negros, que por diversos motivos ainda ocupavam os mesmos espaços físicos do tempo do cativeiro. Por outro lado, os problemas e questões financeiras são subvertidos pelo discurso educacional agrícola, como, por exemplo, a inexistência da discussão sobre salário em meio à fomentação de uma classe trabalhadora livre no recôncavo.

Publicações produzidas por homens importantes do Império acerca dos debates sobre instruções agrícola reforçam os debates sobre escravidão, liberdade e instrução agrícola, como as séries de livros encontrados na Biblioteca do Senado Federal, em especial o intitulado: A instrução agrícola e o trabalho livre, escrito por Domingos Maria Gonçalves, que, dentre outras atribuições, intitulava-se cônsul de Portugal e fundador do Jornal da Província (RJ). No texto composto de 70 páginas, ele discute a importância e as estratégias para consolidação da "verdadeira liberdade" aos "recém-libertos" da nação. Chama a atenção uma carta destinada ao "Exmo. Sr. Dr. Joaquim Nabuco, deputado geral", onde Domingos, dentre outras reflexões, considera:

Eu também sou abolicionista, o Jornal da Província que fundei e existe ainda em Campo, (o município do Império que tem o maior número de escravos), foi no seu tempo a primeira e única folha franca e lealmente abolicionista, mas estou cada vez mais convicto, que não basta dar a liberdade a indivíduos semibarbarisados pela triste instituição onde viveram, torna-se urgentíssimo crear desde já estabelecimentos agrícolas nos quais se prove aos fazendeiros, que o trabalho livre não é uma utopia, onde se preparem os futuros diretores técnicos das grandes fazendas, e ao mesmo tempo que se forneçam trabalho remunerado e alguma instrução aos que saírem do cativeiro [...] Os libertos não se prestam, em regra, a trabalhar em lugares onde estiverem escravos. Tudo ali Ihes recorda os seus sofrimentos passados. Tais razões me forçam a publicar este opúsculo. Libertem-se os negros, mas dê-se escolas agrícolas a este povo. Uma coisa sem a outra é a ruína completa de toda a nação. ${ }^{42}$

Em uma primeira análise, pode-se conjecturar sobre o perfil que é desejável instruir mediante aos ensinamentos agrícolas. Para Domingos, o alerta é feito no sentido de que a libertação do trabalho escravo possibilitaria uma nova organização econômica dessa mesma força de trabalho. Outra publicação, cuja autoria é atribuída a Caetano Alberto Soares, membro do conselho diretor do Instituto dos advogados brasileiros, menciona os esforços para acompanhar a "sorte dos escravos", pouco antes da abolição:

A justiça ordena, é verdade, e a humanidade requer que a liberdade seja dada aos escravos, sempre que Ihes possa ser conferida, sem transtorno das fortunas e da ordem pública, e sem ofensa dos direitos legalmente adquiridos. Mas a liberdade sem preparação acomodada, é antes um verdadeiro mal, que não um bom, para os escravos, que nela caem por semelhante feitio. Essa liberdade

\footnotetext{
42 GONÇALVES, Domingos Maria. A instrução agrícola e o trabalho livre. Rio de Janeiro: Typ. Central de Evaristo Rodrigues da Costa, 1880. Disponível em: http://www2.senado.leg.br/bdsf/handle/id/4/discover. Acesso em: 08 nov. 2018.
} 
fortuitamente obtida, e improvisada, conduz direito, e quasi inevitavelmente, como a experiência todos os dias o confirma, ao ócio inerte, à degradação brutal, à miséria por fim, e ao acervo de todas as moléstias físicas; e este estado, quer se considere com relação às pessoas quer em relação à sociedade, é mil vezes pior que a escravidão, onde (ao menos) a miséria nunca aparece, onde a enfermidade é sempre assistida, e onde a ociosidado com sua detestável sequela não acha guarida. ${ }^{43}$

A "verdadeira liberdade" para os recém-libertos seria, segundo ele, um abolicionista, continuar de modo "técnico" a manutenção da lavoura açucareira, ou seja, a reinvenção de novos processos nas relações de trabalho, sem o abandono da lavoura, porém com o abandono das experiências de "embrutecimento" no mundo do trabalho oriundas da escravidão. Nesse sentido, o trabalho assalariado na agricultura começa a ter origem nesse percurso da formação do operariado agrícola. A partir de 1870 até o fim do Império, houve um aumento em diversos ramos que caracterizaram um crescimento industrial na Bahia, gerando grandes necessidades de educação popular, preocupação que iria se estender durante a República.

A interpretação historiográfica desenvolvida por Silvia Hunold Lara, Sidney Challhoub e potencializada por Alvaro Nascimento, no que chamaram de "paradigma da ausência", pode ser articulada a tal contexto, no sentido de estimular a compreensão e investimento em agendas comuns de reflexões que se apropriem do aparato clássico da história social, porém centrada na ideia de classes, lutas de classes, raça, gênero, geração, ideologias, hegemonia, etc. ${ }^{44}$

Vários também são os trabalhos de historiadores que escreveram sobre o recôncavo baiano, muitos deles destacando que o cultivo da cana-de-açúcar determinou, por mais de 400 anos, os usos dos espaços e ditou as relações de trabalho, profundamente marcadas pela escravidão e posteriormente pela tentativa de inserção desses sujeitos egressos nas dinâmicas do trabalho livre. Sendo importante pontuar que muitos desses trabalhos são essenciais para a compreensão histórica do lugar. Porém, muitas dessas obras abordaram o recôncavo baiano de maneira geral e, por conta dessas demandas, o recorte específico para São Francisco do Conde (nesse cenário de pesquisa e produção historiográfica) ainda é pouco explorado. Identificando tais lacunas é que a pesquisa insere-se, promovendo o diálogo com os estudos da escravidão, pós-abolição e mundos do trabalho, assim como buscando aparatos que promovam a

\footnotetext{
43 SOARES, Caetano Alberto. Memória para melhorar a sorte dos nossos escravos. Lida na sessão geral do Instituto dos Advogados Brasileiros, no dia 07 de setembro de 1845. Rio de Janeiro, 1847. Disponível em: http://www2.senado.leg.br/bdsf/handle/id/174460. Acesso em: 09 nov. 2018.

${ }^{44}$ No artigo "Escravidão, cidadania e história do trabalho no Brasil", da historiadora Sílvia Hunold Lara, é dado enfoque aos aspectos da exclusão dos negros (escravos ou ex-escravos) da história social do Brasil, que passou a ser a história do trabalho livre e assalariado/operário. Em "Sujeitos no Imaginário acadêmico: escravos e trabalhadores na historiografia brasileira desde os anos 1980" os historiadores Sidney Chalhoub e Fernando Teixeira da Silva analisam a historiografia produzida a partir da década de 1980, identificando, na experiência dos escritos de historiadores brasileiros sobre as dinâmicas da categoria de trabalho, lacunas em relação a outros modelos nacionais. E, por fim, em "Trabalhadores Negros e os 'paradigma da ausência': contribuições à História social do trabalho no Brasil", o historiador Álvaro Pereira Nascimento recupera e potencializa a análise de tal paradigma, expondo a necessidade da historiografia acerca dos mundos do trabalho no Brasil perceber e dialogar com as experiências dos estudos sobre escravidão, reconhecendo também as contribuições em termos de metodologias e problemas.
} 
sensibilidade ao destacar as experiências negras nesses contextos, tanto em escala local quanto global.

Os interesses demonstrados pela Secretaria de Estado dos Negócios da Agricultura, Comércio e Obras Públicas, criada em 1860, relaciona-se com a questão "da substituição da mão de obra cativa ganhou relevância nos debates nacionais, estimulando a politica de imigração". ${ }^{45}$ No entanto, como já foi sinalizado, a mão de obra nacional no Nordeste foi bem mais aproveitada em detrimento das estratégias com os processos de imigração europeia no Sudeste. Era fruto das preocupações dessa secretaria acompanhar o entendimento perante a crise na agricultura dessas regiões, a partir da realização do Congresso Agrícola de 1878, fomentando debates entre congressistas do Rio de Janeiro e Recife. O entendimento e as estratégias utilizadas entre essas duas províncias ficou explícita no tipo de "substituição" que julgaram adequada ter a mão de obra ao final da escravidão, e nos rumos da instrução agrícola, sendo que os recifenses: "acreditavam que os ingênuos seriam um elemento importante para o desenvolvimento da agricultura, desde que convenientemente educados em escolas agrícolas [...] conjuntamente com crianças órfãs". ${ }^{46}$

A instrução vinculada ao processo de pós-abolição contribuiu e gerenciou a manutenção da estrutura geral de modelo monocultor e escravista, embora começasse a adentrar as esferas da industrialização. Esse molde escolar herdara aspectos que prolongavam a subalternização de "aprendizes" de trabalhadores ao passo que também desenvolvia uma importante instituição de ciência. Obviamente, o caso baiano expõe especificidades próprias das elites locais e das conexões com outros espaços coloniais. Esses elementos tornaram a EAB como instituição central no âmbito de disputas por projetos políticos e educacionais, cuja participação de diversos personagens orientou a sua trajetória para compor um grande capítulo na história da Bahia.

\footnotetext{
45 GABLER, Louise. A secretaria de estado dos negócios da agricultura, comércio e obras públicas e a modernização do Império. Rio de Janeiro: Arquivo Nacional, 2012.

${ }^{46}$ FONSECA, Marcos Vinícius. Escolas para crianças negras: uma análise a partir do congresso agrícola do Rio de Janeiro e do congresso agrícola do Recife, em 1878. Anais [...]. Congresso da Sociedade Brasileira de História da Educação. Belo Horizonte, 2004.
} 


\section{Referências Bibliográficas}

ABREU, Martha; MARTINEZ, Alessandra Frota. Olhares sobre a criança no Brasil: perspectivas históricas. In: RIZZINI, Irene (org.). Olhares sobre a criança no Brasil - séculos XIX e XX. Rio de Janeiro: Amais, 1997.

AZEVEDO, Célia Maria Marinho. Onda Negra, medo branco: o negro no imaginário das elites, século XIX. Rio de Janeiro: Paz e Terra, 1987.

BARICKMAN, B. J. Até a véspera: o trabalho escravo e a produção de açúcar nos engenhos do Recôncavo Baiano (1850-1881). Revista Afro-Ásia, Salvador, n. 21-22, p. 177-238, 1998-1999.

BARICKMAN, B. J. E se a casa-grande não fosse tão grande? uma freguesia açucareira do recôncavo baiano em 1835. Afro-Ásia, Salvador, n. 29-30, p. 79-132, 2003.

BARICKMAN, B. J. Um contraponto baiano: açúcar, fumo, mandioca e escravidão no Recôncavo, 17801860. Rio de Janeiro: Civilização Brasileira, 2003.

CAPDEVILLE, Guy. O Ensino Superior Agrícola no Brasil. R. bras. Est. pedag., Brasília, v. 72, n. 172, p. 229-261, set.-dez. 1991.

CHALHOUB, Sidney; SILVA, Fernando Teixeira. Sujeitos no Imaginário Acadêmico: escravos e trabalhadores na historiografia Brasileira desde os anos 1980. Cad. AEL, v. 14, n. 26, 2009.

CONRAD. Robert. Os últimos anos de escravatura no Brasil. Rio de Janeiro: Civilização Brasileira, 1978.

CUNHA, Mário Pinto. Memorial de São Francisco do Conde. Salvador: Ed. Central, 1976.

DEAN, Warren. A ferro e Fogo. A história e a devastação da Mata Atlântica brasileira. São Paulo: Companhia das Letras, 1996.

FONSECA, Marcos Vinícius. A educação dos negros: uma nova face do processo de abolição da escravidão no Brasil. São Paulo: EDUSF, 2002.

FRAGA FILHO, Walter. Encruzilhadas da liberdade. História de escravos e libertos na Bahia (1870-1910). Campinas: Ed. Unicamp, 2006.

FRAGA FILHO, Walter. Mendigos, moleques e vadios na Bahia do século XIX. São Paulo: Hucitec, 1996.

GABLER, Louise. A secretaria de estado dos negócios da agricultura, comércio e obras públicas e a modernização do Império. Rio de Janeiro: Arquivo Nacional, 2012.

KOWARICK, Lúcio. Trabalho e vadiagem: a origem do trabalho livre no Brasil. São Paulo: Brasiliense, 1987.

KURY, Lorelai. Homens de ciência no Brasil: impérios coloniais e circulação de informações (1780-1810). História, Ciências, Saúde - Manguinhos, Rio de Janeiro, v. 11, supl. 1, p. 109-129, 2004.

LARA, Sílvia. Escravidão, Cidadania e História do Trabalho no Brasil. Proj. História, São Paulo, n. 16, fev. 1998.

LIMA, Henrique Espada. Sob o domínio da precariedade: escravidão e os significados da liberdade de trabalho no século XIX. Topoi, v. 6, n. 11, p. 289-362, jul.-dez. 2005. Disponível em: http://www.revistatopoi.org/numeros_anteriores/Topoi\%2011/topoi11a4.pdf. Acesso em: 10 dez. 2018.

LOPES, Maria Margareth. O Brasil descobre a pesquisa científica. Os museus e as ciências naturais no século XIX. São Paulo: Aderaldo \& Rothschild; Brasília: Ed. UnB, 2009. 
MARQUESE, Rafael de Bivar. Feitores do corpo, missionários da mente. Senhores, letrados e controle dos escravos nas Américas, 1660-1860. São Paulo: Companhia das Letras, 2004.

MATTA, Alfredo Eurico Rodrigues. Casa Pia Colégio de Órfãos de São Joaquim. De recolhido a assalariado. 1996. Dissertação (Mestrado em História) - Programa de Pós-graduação em História, Universidade Federal da Bahia, Salvador.

MATTOSO, Katia. Ser escravo no Brasil. 3ed. São Paulo: Brasiliense, 1990.

MENDONÇA, Sonia Regina. O ruralismo brasileiro (1888-1931). São Paulo: Hucitec, 1997.

NASCIMENTO, Álvaro Pereira. Trabalhadores negros e o "paradigma da ausência": contribuições à História Social do Trabalho no Brasil. Estudos Históricos, Rio de Janeiro, v. 29, n. 59, p. 607-626, set.-dez. 2016.

NETO, José Pereira de Santana. Sociedade, indenização e liberdade precária: os meandros burocráticos do fundo de emancipação de escravos (São Francisco do Conde-BA). 2018. Tese (Doutorado em História) - Programa de Pós-graduação em História, Universidade Estadual de Campinas, Campinas (SP).

NUNES, Anttonieta d'Aguiar. Sinopse da História da Educação baiana até o Período Imperial. Revista IGHB, Salvador, v. 111, p. 23-57, jan.-dez. 2016.

PARĖS, Luis Nicolau. O processo de crioulização no Recôncavo baiano (1750-1800). Afro-Ásia, n. 33, p. 87-132, 2005.

PINHO, Wanderley. História de um Engenho do Recôncavo. Matoim-Novo Caboto-Freguesia. 1552-1940. $2^{a}$ ed. São Paulo: Companhia Editora Nacional, 1982. (Col. Brasiliana; v. 374).

RODRIGUES, Marcelo Santos. Voluntários da pátria na guerra do Paraguai: a participação da Bahia no conflito. 2001. Dissertação (Mestrado em História) - Faculdade de Filosofia e Ciências Humanas, Universidade Federal da Bahia, Salvador.

SALLES, Ricardo. Capitalismo, Estados Unidos e o tráfico internacional de escravos no século XIX. Almanack, Guarulhos, n. 17, p. 486-493, dez. 2017.

SANSONE, Lívio (org.). Memórias da África: patrimônio, museus e políticas das identidades. Salvador: Ed. UFBA, 2012.

SANSONE, Lívio (org.). Negritude, memória da África e o contraponto do açúcar e do petróleo. Salvador: Ed. UFBA, 2012.

SANTANA, Clíssio. "Ele queria viver como se fosse homem livre": escravidão e liberdade no termo de Cachoeira (1850-1888). 2014. Dissertação (Mestrado em História) - Programa de Pós-graduação em História, Universidade Federal da Bahia, Salvador.

SCHWARTZ, Stuart. Escravos roceiros \& rebeldes. Bauru, SP: EDUSC, 2001.

SCHWARTZ, Stuart. Segredos internos: engenhos e escravos na sociedade colonial. São Paulo: Companhia das Letras, 1988.

SILVA, Eduardo; REIS, João José. Negociação e Conflito. A Resistência Negra no Brasil Escravista. São Paulo: Companhia das Letras, 1989.

SOUSA, Jorge Prata de. A mão-de-obra de menores escravos, libertos e livres nas instituições do Império. In: SOUSA, Jorge Prata de (org.). Escravidão: ofícios e liberdade. Rio de Janeiro: APERJ, 1998.

TAUNAY, Carlos Augusto; MARQUESE, Rafael de Bivar (orgs.). Manual do Agricultor Brasileiro. São Paulo: Companhia das Letras, 2001.

TOMICH, Dale W. Pelo prisma da escravidão. Trabalho, Capital e Economia Mundial. São Paulo: Ed. USP, 2011. 
TOURINHO, Maria Antonieta de Campos. A instrução agrícola e a crise da economia açucareira na segunda metade do século XIX. 1982. Dissertação (Mestrado em História) - Programa de Pós-Graduação em História, Universidade Federal da Bahia, Salvador. 